\title{
Migration Mechanism of Organic Pollutants in National Water-body Sediments
}

\author{
Haiyuan Qiu (Corresponding author) \\ Fujian Monitoring Center of Geological Environment, Fuzhou, 350001, China \\ Tel: 86-136-6609-2205 E-mail: qiuhaiyuan@hotmail.com
}

Received: November 11, 2010 Accepted: November 25, 2010 doi:10.5539/jgg.v3n1p239

\begin{abstract}
Wter-body sediments are a main part of water biological system, sinks and sources of many water-body nutritional substances and pollutants, and carriers, end-results and cumulating places for large amount of contaminants. The article makes a summary of pollution of organic matters in natural water sediments, to provide scientific basis for dealing with polluted sediments.
\end{abstract}

Keywords: Sediments, Organic matters, Pollution, Migration

\section{Introduction}

Pollution of organic matters has become a global problem. Environment Protection Ministry of USA selects 129 toxic pollutants from 70000 kinds of normal compounds, wherein 114 kinds of organic matters (Jin, Xiangcan, 1992) Pollutants are collected increasing into sediments by atmosphere sedimentation, wastewater discharging, and rain pouring, dissolving and washing, resulting in heavy polluted sediments (Ludwig,W. Probst J, \& Kempe, S, 1996). Sediment pollution situation is very severe in Rhine drainage area, Great Lake area of USA, Amsterdam Port of Holland, Hamburger Port of Germany. The worsening situation of sediment pollution is caused by manmade factors. Quite quantities of pollutants, which are difficult for degrading, are accumulated into water sediments during the fast developing process of economics, forming long-term threat on water biological system. When control of pollution resource reaches some degree, sediments will become main sources of water-body pollution (Eatherall, A., Naden, P S. \& Cooper, D M, 1998). EPA of USA pointed out in their survey report in 1998 that much pollution in the 2100 fish consuming problems were proved coming from sediments $(\mathrm{Qu}$, Jiuhui, 2000). Water sediment pollution is a global environmental problem. In our China, toxic organisms are also found and proved existing in water sediments; for example, sediments in 20 -195km section of Changlejiang are toxic (Ma, Mei., \& Tong Zhonghua, 1997). In addition, the key to solve neutralized water-body is also closely related to sediments (Niu, Zhenguo. \& Zhang Zulu, 1997; Wang, Hongdao, 1990). Abundantly growing algae and N,P residues all cumulate in sediments. Heavy metals and toxic organic matters could be objects of micro-pollution water treatment for long time, which are main carriers and media of water complex pollution and its pollution process (Yuan, Xuyin, 2000). So, treatment of polluted sediments is no time to delay and imperative under the situation (Harvey, H. R. \& Mannino, A, 2001).

\section{Pollution situation of sediments}

Water-body sediment (bottom mud) is slit deposited at the bottom of rivers, lakes, reservoirs, bays, and so on. It is a main component of water multi-phase biological system, and gathering place of environmental pollutants in wide space and long time. Interfacial reactions between all kinds of pollutants in sediments and around water solution have crucial influence on water quality. And quality situation of sediments directly affects water quality. So, the importance of estimating the quality of sediments goes without saying (Zhang, Licheng., Zhang, Shen., Dong, Wenjiang., \& Zhao, Guijiu, 1986). Pollutants gathered in the sediments mainly have three kinds: heavy metals, nutritional elements, and uneasily degraded organic matters.

(1) Heavy metals. Metals entering into water by all ways are easily absorbed, complexed, or co-deposited, consequently enriched in the sediments at water bottom, resulting in the concentration of heavy metals in sediments pretty higher than that in water. Zhang Lichent et al. researched the cleaning effects of Xiangjiang sediments on heavy metals in Xiangjiang water. They found that sediment absorption was main mechanism of natural cleaning for heavy metals (Zhang, Licheng., Zhang, Shen., Dong, Wenjiang., \& Zhao, Guijiu, 1986). Cd concentration in sediments of Dianchi Grass Sea reaches $41.3 \mathrm{mg} . \mathrm{kg}^{-1}$ (Jin, Xiangcan, 1995), Zn concentration in 
sediments of some section of Xiangjiang may exceed $3000 \mathrm{mg} \cdot \mathrm{kg}^{-1}$, and that of Pb may be over $2000 \mathrm{mg} \cdot \mathrm{kg}^{-1}$ (Gao, Xingzhai, 1987).Natural gathering indexes of $\mathrm{Cd}, \mathrm{Hg}, \mathrm{Zn}$ in sediments in Qiandao Lake are over 2 times of that of normal value; influenced by the exploitation of $\mathrm{Cu}$ mine in Dexing of Jiangxi, average gathering multiple of $\mathrm{Cu}$ in sediments of Duyang Lake could reach 20-70 times, that of $\mathrm{Pb}$ and $\mathrm{Zn}$ respectively are 6-17 and 2-8.

(2) Nutritional elements. Due to long-time outside resources inputting and depositing of water organism residues, plenty of organic matters, N, P and other nutritional elements are gathered in sediments. For example, content of TOD of sediments in Chinese lakes is within 4.7-145 g. $\mathrm{kg}^{-1}$, total P content in cities is within 1237.6-4504.7 mg.kg ${ }^{-1}$, and Kjeldahl nitrogen is within 2156-25632 mg.kg ${ }^{-1}$ (Jin, Xiangcan, 1995). On one hand, these nutritional substances provide plenty of food resources for water organisms; on the other hand, if the contents of these nutritional substances are too high and distributed into water in large amount, causing up-water in rich nutrition situation, it will result in degeneration of water biological system. For example, P released by sediments to West Lake of Hangzhou occupied 41.5\% of P from outside resources during July 1988 and June 1989 (Han, Weiming. \& Zhang, Guoxun, 1990). Due to the influences of inner P resources, the effects of water-inputting for West Lake disappeared in 10 days after shutdown (Wu, Genfu., Wu, Xuelü. \& Jin, Chengtao, 1998). A research on one lake of Sweden showed that 99\% nutrition in the lake in summer come from self-sediments (Allan, R J, 1986), more important is, even exterior resources of water nutrition were well controlled, the seasonal re-suspending of nutrition in sediments still could making the rich nutrition situation still lasting for several decades(Morris,J T., Bowden, W. B. \& A. mechanistic, 1986).

(3) Organic matters difficultly degraded. The harm of toxic organic pollutants to water biological system becomes more and more severe in recent years. PAHs, PCBs, and organic chloride were kept being found in water, sediments, and water-living organisms. According to the survey on Songhua River and Baiyangdian by Chu Shaogang, Xu Xiaobai, Dou Wei, it was found that the contents of DDT, BHC, PCBs and other organic pollutants were quite high in the water, and that in sediments and fish bodies were much higher than that in the water, some even higher over 1000times (Chu, Shaogang., \& Xu, Xiaobai, 1995; Dou, Wei., \& Zhao, Zhongxian, 1997). Increasing toxic organic matters in water cause severe influence on water biology. For salmonid in 5 large lakes of USA, it was found that more and more of them were suffering from hypothyroid cancer, resulting in their numbers decreased; hatch-out rate and numbers of crocodiles in Florida and USA terns in Lake Michigan were decreasing. These abnormal phenomena were suspected caused by environmental hormones such as PAHs, PCBs and organic chloride pesticides. Most of these organic substances in water of lakes and rivers were caused by pesticides used in farm lands. They also could be transferred to human beings through food-chain. Therefore, the harm of them was great.

According to the estimation by EPA of USA, pollution levels of $10 \%$ water of USA have been enough to threaten potentially to fishes, human being and wild creatures which eating these fishes, that is, among 12 billion cubic yard $(1$ yard $=0.914 \mathrm{~m})$ water sediments, 1.2 billion cubic yard sediments were polluted seriously. Among 0.3 billion cubic yard sediments dredged-up in USA each year, about 3-12 million cubic yard of them are polluted sediments (Smith, S. C., Ainsworth, C. C. \& Traina, S. J, 1992).

In addition to the polluted sediments, due to more severely human activities, many water sediments still face the threat of being polluted. Water sediments of 96 drainage areas are facing the threat of being polluted, according to the survey of USA EPA for 1372 drainage areas among 2111 ones (Kefford, B., kjelleberg, S. \& Marshall, K. C., 1982).

\section{Organic pollution of sediments}

In recent years, organic pollution on environments is a focused topic globally. Many kinds of organic pollutants increase with an unimaginable speed each year. Many organic matters, which were not been focused before, were listed as pollutants now. and that worries human being a lot is that it is more and more difficult to confirm what kind of substances are not pollutants on earth, especially for vast and numerous organic matters. The appearance of current all kinds of strange organism diseases and physiological phenomena were considered relating to severe environmental pollution to large degree. However, the seriousness of organic pollution was observed originally from researches for water-living organisms. Affected by pesticide drains of organic chlorine and phosphor from pesticide factories, bottom-living creatures of Duck Lake in Hubei are not many. Aulodrilus plurisetas, which are able to bear pollution, have absolute predominance. Below Am of the drainage outlet, there were nearly no bottom-living creatures (Jin, Xiangcan, 1995; Gao, Xingzhai, 1987).

\subsection{Environment hormones}

Abnormity of genitals of male cyprinoids in Florida is occurred, hatch-out rates of cyprinoids are reduced; many abnormal male sea-gulls, which are short of procreation ability, were found in Canada; some cyprinoids, which 
bodies have both male and female organs, were found in some rivers and valleys in Japan and British; Seals in Holland has weak immunity and their numbers are decreased gradually, testicles of some see dogs in Africa were resorted in their abdomens. Human beings couldn't avoid this kind of global "female booming and male declining"; the survey results of more than 20 countries of France, USA, British, Japan, and so on by Danish scientists showed that: From 1940 to 1990, density of germ cells of human being decreased 50\%, amount of semen liquid reduces $25 \%$. Currently, in western countries, about $20 \%$ couples are suffering from no-kids. It is forecasted that $50 \%$ men in 21 century will lose the procreation ability.

A report of World Wild Creature Fund Association in 1998 said that: if taking global animal index in 1970 as 100 , that of 1995 had reduced to 68 . Only in 25 years, $32 \%$ creatures were exterminated. In this period, ocean organism index reduced $30 \%$, that of fresh water biological system of rivers, lakes, swamps, and marshes reduces $50 \%$ ! This mainly resulted from industrial pollution. Most severe areas for creature annihilation are USA, China, India, Brazil, Australia, North and east Africa. People think this is the biggest catastrophe suffered since from the extinction of dinosaurs on the earth. Harmful pollutants spread in atmosphere, water, and soil not only cause organism dying from toxicosis, but also result in decrease of multiply ability and numbers, consequently causing species extinction. This is the most terrible future.

When people are trying to look for the chief criminals of imbalanced biology, species extinction, and femalizing trend, which result in extremely panic to people, a new term-"environment hormones" is created. Environment hormones, which traces back to estrogen harm in early report in iatrology field, are chemical substances which are released to the environments due to production and living activities of human being and influence normal hormones originally created by human beings and creatures, consequently affecting incretion systems, generally called "outside chemical substances affecting incretion". All these chemicals have weak hormone-like functions, possibly influencing procreation, genitalia cancers, sex actions, also immunity and nerve systems.

Now, about 10 million kinds of chemical substances have been synthesized, and about 100 thousands chemical substances are newly synthesized each year. These chemical substances enter into environments inevitably during the process of their production, storage, transportation, and utilization and cause environment pollution, for example, organic chlorine pesticides, multi-chlorine diphenyl, phenols, and so on. However, not all the chemical substances are environment hormones. According to the research by Wang Yuxiu,Caro (USA), et al, there are about 70 kinds of chemical substances which could interfere incretion, wherein, about over 40 kinds are components of pesticides. There still many chemical substances which need tobe examined or verified whether they interfere incretion system or not, for example: 2, 4-dichlorine phenol, diphenyl ketone, n-butylbenzene, etc. Presently, there are about over 200 kinds of chemical substances were suspected having direct influence on human health. Over 70 kinds of chemical substances have been verified and listed in the blacklist of environment hormones, including metal substances $\mathrm{Cd}, \mathrm{Pb}, \mathrm{Hg}, 24$ kinds of pesticides with organic chlorine and phosphor, 10 kinds of weedicides, 9 kinds of bactericides, 9 kinds of plasticizers, preservatives, fire retardant, dopes, and so on. It could be seen from the blacklist that 67 kinds of substances are organic except for $\mathrm{Cd}, \mathrm{Pb}$, and $\mathrm{Hg}, 3$ kinds of metals, and 44 kinds of substances are pesticides (24 kinds of insecticides, 1kind of metabolized outcomes of insecticides, 10 kinds of weedicides, 9 kinds of bactericides), occupying $65.7 \%$ of 67 kinds of environment hormones.

Environment hormones are widely existed in daily life, for example: things based on PVC, PS convenient boxes containing styrene, antisepticizing film inside metal cans, synthesized detergent, cosmetics, pesticides, and their degrading outcomes, pollutants from rubbish burning, etc. Environment hormones are yielded during the production activities of human beings. The fundamental countermeasure to prevent environment hormones is not to release chemical substances to environment and put an end to the original sources of environment hormones; not to burn rubbishes; to strictly control the use of pesticides to ensure food safety for human beings and animals.

\subsection{Persistent organic pollutants}

Persistent Organic Pollutants (for short as Pops) are organic chemical pollutants, which are toxic, gathering in organisms, half-volatile, persistently existing in environment, able to migrate long distances in atmosphere environment and aggregate back to polar region of the earth, severely harmful to human health and environment. According to international definition of POPS, these substances must accord with the following conditions: (1) durable in their releasing and transport environment; (2) could be gathered in the food chain and affect organisms with high nutritional values; (3) after entering into environment, could be moved to polar areas across long distances; (4) in corresponding environment concentration, be harmful or toxide to organisms which contacting the substances (Li, Zhengyu, 1999). 
In 1997, UNEP pointed out international actions shall be taken for 12 kinds of POPS, including aldrine, dieldrin, isodieldrin, DDT, chlordane, hexachlorobenzene, mirex, strobane, heptachlor, polychlorinated biphenyls, dioxin and chromene. Wherein, the fore 9 kinds are pesticides, polychlorinated biphenyls is industrial chemical, the last two are impurity ramification of chemicals and residues of burnt chlorine wastes. Most of the 12 substances have high urgent toxicity and are toxic to water-livings; one of them is human cancer-causing, which has been confirmed by international cancer research organization. 7 of them are potential cancer-causing substances, half life of them in water mostly are 1-12 years, individually as long as 600 years, and BCF is within 4000 70000. In the Extensive Europe Environmental Conference of June 1998, 32 countries of USA, Canada and Europe countries signed an agreement on long-distance atmosphere pollutants across boundaries formally. The agreement forbids or reduces releasing of POPS and forbid and gradually eliminate the production of some products which containing POPS. There are 16 kinds of controlled Pops, in addition to 12 kinds put forward by UNEP, also including hexabromodiphenyl, chlordane /BHC, polycyclic aromatic hydrocarbons, penta.

Pops pollution is a more and more serious environmental problem (Poeton, T. S., Stensel, H. D. \& Strand, S E., 1999). At every corners, including continents, deserts, oceans and polar areas, Pops substances could be inspected there (Mcnally, D. L., Mihelcic, J. R., \& Lueking, D. R, 1999; Joint, I. R. \& Pomroy, A. J., 1982).From current known data, concentrations (ng/g wet weight) of POPS in mammals in north pole area respectively are: DDT 239000; dioxin 300118000; chlordane 0.67096, polychlorinated biphenyl 112900 and strobane 84-91600. Because POPS could be gathered and enlarged in food chain, they influence creatures, at the top of food chain a lot, including human beings. In fact, in her typical work Silent spring, Rachel Carson had mentioned that the decrease of birds in numbers might relate to the use of pesticides. Some reports had showed that organic chlorine, especially degraded outcomes of DDE and DDT, could affect the thickness of eggshells of birds, having profound influence on birds which eat fishes (Plummer, D. H., Owens, N. J R. \& Herbert, R. A., 1987). Decrease of propagating ability of seals in Baltic Sea and whales of Canada may be related to Pops, mainly are PCBs.

POPS also are substances which cause turbulence of "sex hormones" and "incretion hormones". In addition to their influence on procreation, many POPS tested or suspected are cancer-causing substances, wherein PAH and PCDD/Fs(Dibenzo-p-Dioxin /diphenylene-oxide) may be typical examples. Influences of PCDD/Fs on health have become a large research subjects. USA Environment Protection Ministry and other many Europe counties have invested a lot on the research to prove up the co-function of many POPS on organisms (Ploug, H. H., Zimmermann, T. \& Schweitzer, B., 2002). This will be a research direction of toxicology in recent years.

\section{Transfer and transform rules of organic pollutants in water}

Organic pollutants, which enter into water, could cause all kinds of physical and chemical changes in water. The rules of these changes and the end-results have important influence on their toxicity. So, the task of chemistry of environment pollution is to find the transfer and transform rules to provide theory references and practical bases. After entering into water, organic pollutants were distributed to phases of water, suspending particle, water-living organism, and sediment, which have the following rules and trends.

\subsection{Distribution of organic pollutants in water}

Presently, most of organic pollutants, which are focused and quite harmful to environment, could persistently exist in water and have strong hydrophobicity. After complex physical, chemical and biological changes, organic pollutants which could persistently exist in sediments mainly are some Pops, and quite a lot of these pops are foregoing environment hormones.

Most of pops have strong hydrophobicity, which are easily absorbed by particles in water. Pops are not only absorbed to the surface of particles, but could enter into the interior part of the particles, i.e., the dissolving process towards to the interior part of the particles. Organic substances absorbed to the surface have some exchanging and lixiviating properties, being a reversible absorption part; whereas the organic carbon part entering into the inside of particles forming a irreversible absorption part, difficult for lixiviating (Pierre, S. \& Josette, G., 2006), entering into sediments with the dropping of particles. The proceeding of this kind of sedimentation is heavily influenced by water quality and waterpower conditions. Water temperature, salinity, $\mathrm{pH}$ and other terms could affect the proceeding of absorption and desorption processes of organic substances and the water stream could severely affect the dropping of particles. Organic pollutants have different transfer ability in different water bodies. Water in pretty immobile rivers or lakes, where the water is stable and has not much disturbance, is propitious to the dropping of particles. Organic pollutants are easily sedimentated not far from the discharging sources in the water (Wang, H. J., Yang, Z. S. \& Li, Y. H., 2007). However, in water where stream is rushing, change of water quality is big, and the activities of water-living creatures are blooming, organic pollutants in this kind of water may move a long distance and exist in long term, making the contents of organic 
substances high and pretty harmful to water-living creatures. At the same time, particles which dropped into the sediments may suspend into water again under the function of all kinds of water powers and disturbances of water creatures, forming second water pollution. Organic pollutants may be transferred to a very far place through this kind of repeated sedimentation-suspending process (Mcnally, D. L., Mihelcic, J. R., \& Lueking, D. R., 1999).

$\mathrm{Xu}$ and other people researched the pollution characteristics of chloride organic pollutants in sediments in Yangtse River (Nanjing section), founding that the pollution degree of different sediments are DDTs $>$ HCB $>$ HCHs > PCBs. Generally speaking, the contents of organic chloride sediments in the section of Yangtse River are lower than that of rivers in Europe. Contents of organic chloride sediments are closely related to the contents of organic matters and heavy metals in sediments (Paolo, M., Shigeru, M., \& Kuninao, T., 2002).

Lee and other people researched the pollution characteristics of chlorobenzene, BHC and heavy metals, finding that there are very good correlation between chlorobenzene and other organic pollutants, but the correlation to heavy metals is not obvious, which shows that heavy metals and organic pollutants in sediments in maritime spaces with frequent human activities (Blumer, M., Guillard, R .R. \& Chase, T., 1971).

Qiu Zunan other people researched the average content and distribution characteristics of EPA priority pollutants in Suzhou River of Shanghai, finding that the average contents of PAHs (13 kinds) and single chlorine hydroxybenzene (including dichlorine and tetrachloro phenol) respectively are $14.99 \mathrm{mg} \cdot \mathrm{kg}^{-1}$, and $8.63 \mathrm{mg} \cdot \mathrm{kg}^{-1}$, occupying 99.5 of the total amount of EPA priority pollutants in Suzhou River and the distribution characteristics is quite in consistent with the distribution characters of heavy metal pollution (Qiu, Zunan., Zhang, Zhongyan. \& Qi, Deyao, 1998).

Zhang Bing and other people measured the PCP in water an sediments of Dongting Lake, founding the contents of PCP within 0.005-71.3 ug.g ${ }^{-1}$, that of sediments within 0.18-48.3 ug. $\mathrm{g}^{-1}$, showing PCP mainly distributed to sediment phase, whose contents obviously higher than that of other using areas of Sichuan, Jiangsu and Fujian, though PCP stopping bejing used. At the same time, PCP contents in over covering water and sediments have some correlation trend, but not strictly positive one. However, the survey during the same period of abalones, grass fish,and cyprinoids shows that the content of PCP in fish cholecysts is high in high-PCP contained water, in the range of 0.06-0.034 ug. $\mathrm{g}^{-1}$ (Zhang, Bing., Zheng, Minghui., Liu, Fanyan., Bao, Zhicheng \& Xu, Xiaobai, 2001).

\subsection{Degradation of organic pollutants}

Most research on degradation of organic pollutants in sediments are carried out in labs, for degrading speed of some POPS is very slow, and the absorption of sediments further reduces the degrading of organic substances. Researches by Poeton and other people found that the biological degradation of phenanthrene and fluoranthene was obviously influenced by the absorption of ocean sediments (Eglinton, G., \& Hamilton, R. J., 1963). Absorption of sediments slows the speed of biological degrading. Because desorption step in the last period of organic substances from sediments to liquid phase forms the speed-control step, making the whole biological degrading process a two-stage process (Rieley, Q., Collier, R. J. \& Jones, D. M., 1991). In real pollutant sediments, the biological degradation becomes more complicated for co-existing of many kinds of pollutants. McNally and other people found that could accelerate the degrading of phenanthrene and flowers, but phenanthrene could restrain the degrading of flowers in aerobic conditions; in anaerobic conditions, degrading of phenanthrene and flowers becomes very slow (Vollcman,J K., Johns,R B., \& Gillan,F T. (1980); in facultative conditions, as receiver of substitute electrons, could speed up the degrading of low molecular-weight polycyclic aromatic hydrocarbons, but the degrading of high molecular-weight polycyclic aromatic hydrocarbons was weak (Luo, X J., Chen, S J., \& Mai, B X., 2005).

Jia Qingzhu and other people researched dynamic characteristics of anoxybiotic degradation of r-666 of Liaohe sediments, finding that the degradation of $\mathrm{r}-666$ accords with quasi first class dynamic equation both in the situation without adding outside carbon sources and with adding outside carbon sources of dextrose, sodium acetic etc. The degrading rate with outside added carbon is higher three times than that without outside added carbon sources, main degrading product is dichlorobenzene (Jia, Qingzhu., Quan, Xie., Chen, Shuo., Chen, Jingwen., Xue, Daming., \& Zhao, Yazhi, 2000)!

Main measure of handling pollution sediments is to move-treat sediments after dredge-up them. Although some microorganisms, after pure-culturing, are found being able to decomposing organic substances of PAH, PCBs and so on, but the results of making products which could decompose organic matters on-site are not ideal presently (Jones, D M., Rowland, S J., \& Douglas, A q., 1986). 


\subsection{Effects of organic matters on organic pollutants}

Environmental actions of organic pollutants, which enter into sediments, mainly are influenced by organic matters in the sediments. Ab-Razak and other people found that distribution of PAHs in sediments mainly are influenced by organic matters (Yunker, M B., \& Macdonald, R W., 1995). Wu and other people found that vertical distribution of BHC in sediments of Duck Lake of China mainly are influenced by contents and particle distribution of organic matters (Berge, J P., Gouygou, J P., Dubacq, J P., \& Durand, P., 1995). Zhu Lizhong and other people researched the absorption mechanism of aniline and phenol, finding that the absorption ability of West Lake sediments for aniline is in direct ratio to content of organic matters, with correlation coefficient 0.998 (Zhu, Lizhong., Xu, Xia., \& Hu, Xiong, 2000).

Organic matters in sediments also heavily affect the biological toxicity of organic toxic substances. Karuppiah and other people researched the toxicity of metolachlor in river sediments for Vibrio fischeri, finding that LC50 of the weedicide for Vibrio fischeri in water is 2.22, that in river sediments reducing 30times, that in wetlant, where having higher degree of decaying, almost losing completely (Gaskell, S J., \& Eglinton, G., 1975). McKenzie and other people found that over $70 \%$ dieldrin were quite easily absorbed by surface sediments which could float easily. Hydrologic features of rivers become the main factor which controls the distribution of dieldrin in sediments. Most of the DDT is bonded to large-molecule organic matters in sediments (Saliot, A., Mejanelle, L., \& Scribe, P., 2001). Gao and others found that On-site Koc of weedicides in sediments measured is much lower than that measured in labs, illuminating that DOC in sediments absorbing weedicides, resulting in the concentration increase of weedicides in hole water. The kind of "concentration increase effect" enhances the organism usability and retransferring ability of weedicides in water (Canuel, E A., \& Zimmerman, A R., 1999). Drouillard and others researched the organism absorption coefficients and BSAFs of 17 kinds hydrophobic organic chlorine compounds (including $\mathrm{PCB}, \mathrm{HCB}$, etc.) with logKow in 5.4-7.4 through larva exposure methods, finding that the biological gathering of hydrophobic organic chlorine compounds with $\operatorname{logKow}>5.9$ was carried out by organisms incepting sedimentated organic matters which absorb hydrophobic organic chlorine compounds (Kvenvolden, K A., Rapp, J B., \& Margaret, G., 1987).

\section{Acknowledgement}

This research was financially supported by Xiamen science and technology project (Grant No. 3502Z20063007), a grant from the Major Program for Fujian coastal economic zone ecological geochemistry of the Ministry of Land and Resources, China (Grant No. 1212010310307), and the National Department Public Benefit Research Foundation (No.201111020-2).

\section{References}

Allan, R J. (1986). The role of particulate matter in the fate of contaminants in aquatic ecosystems. Inland Waters Directorate (Canada) Scientific Series, 142.

Berge, J. P., Gouygou, J. P., Dubacq, J. P., \& Durand, P. (1995). Reassessment of lipid composition of the diatom, Skeletonema sostatum. Phytochemistry, 39, 1017-1021. doi:10.1016/0031-9422(94)00156-N, http://dx.doi.org/10.1016/0031-9422(94)00156-N

Blumer, M., Guillard, R. R., \& Chase, T. (1971). Hydrocarbons of marine phytoplankton. International Journal of Life in Oceans. Coastal Waters, 8, 180-183.

Canuel, E. A., \& Zimmerman, A. R. (1999). Composition of particulate organic matter in the southern Chesapeake Bay: sources and reactivity. Estuaries, 22, 980-994. doi:10.2307/1353077, http://dx.doi.org/10.2307/1353077

Chu, Shaogang., \& Xu, Xiaobai. (1995). Environmental Distribution and Actions of Polychlorinated Biphenyls in Typical Polluted Area. Journal of Environmental Science, 15(4), 423-432.

Dou, Wei. \& Zhao, Zhongxian. (1997). Biological Concentration Analysis of BHC and DDT in Water-living Food Chain of Baiyangdian. Environmental Science, 18(5), 41-43.

Eatherall, A., Naden, P. S. \& Cooper, D. M. (1998). Simulating carbon flux to the estuary: The first step. The Science of the Environment, 210/211, 519-533.

Eglinton, G. \& Hamilton, R. J. (1963). The distribution of alkanes. In: Swain, T. (Ed.), Chemical Plant Taxonomy. New York: Academic Press.pp.187-217

Gao, Xingzhai. (1987). Heavy Metal Pollution Features of Xiangjiang.In: Chen,Duansheng., Huang, Yukai., Gao, 
Xingzhai., \& Zhang, Yuqing (Eds.), Researches of Heavy Metal Pollution of Rivers. Beijing: China Environmental Science Press, 69-79.

Gaskell, S. J., \& Eglinton, G. (1975). Rapid hydrogenation of sterols in a contemporary lacustrine sediment. Nature, 245, 209-211. doi:10.1038/254209b0, http://dx.doi.org/10.1038/254209b0

Han, Weiming. \& Zhang, Guoxun. (1990). Simulation Research of Released Phosphor in Bottom Slit in West Lake of Hangzhou. Paper Collection of Researches of Environment of West Lake, 83-89.

Harvey, H. R., \& Mannino, A. (2001). The chemical composition and cycling of particulate and acromolecular dissolved organic matter in temperate estuaries as revealed by molecular organic tracers. Organic Geochemistry, 32, 527-542. doi:10.1016/S0146-6380(00)00193-5, http://dx.doi.org/10.1016/S0146-6380(00)00193-5

Jia, Qingzhu, Quan, Xie, Chen, Shuo, Chen, Jingwen, Xue, Daming, \& Zhao, Yazhi. (2000). Anoxybiotic Degrading Dynamics of Lindane in Sediments of Liaohe. Environmental Science, 21(3), 44-47.

Jin, Xiangcan. (1992). Chemistry of Sediment Pollution. Beijing: China Environmental Science Press. (Chapter 2).

Jin, Xiangcan. (1995). Environment of China Lakes. Beijing. China Ocean Press. (Chapter 5).

Joint, I. R., \& Pomroy, A. J. (1982). Aspects of microbial heterotrophic production in a highly turbid estuary. Journal of Experimental Marine Biology and Ecology, 58, 33-46. doi:10.1016/0022-0981(82)90095-8, http://dx.doi.org/10.1016/0022-0981(82)90095-8

Jones, D. M., Rowland, S. J., \& Douglas, A q. (1986). An examination of the fate of Nigerian crude oil in surface sediments of the Humber Estuary by gas chromatography and gas chromatography-mass spectrometry. International Journal of Environmental Analytical Chemistry, 24, 227-247. doi:10.1080/03067318608076473, http://dx.doi.org/10.1080/03067318608076473

Kefford, B., kjelleberg, S., \& Marshall, K. C. (1982). Bacterial scavenging utilization of fatty-acids localized at a solid liquid interface. Archives of Microbiology, 133, 257-260. doi:10.1007/BF00521286, http://dx.doi.org/10.1007/BF00521286

Kvenvolden, K. A., Rapp, J. B., \& Margaret, G. (1987). Multiple sources of alkanes in Quaternary oceanic sediment of Antaretiea. Organic Geochemistry, 11 (4), 291-302. doi:10.1016/0146-6380(87)90040-4, http://dx.doi.org/10.1016/0146-6380(87)90040-4

Li, Zhengyu. (1999). International Control Trends and Countermeasures for Persistent Organic Pollutants. Modern Chemical Engineering, 19(7), 5-9.

Ludwig, W. \& Probst J, Kempe, S. (1996). Predicting the oceanic input of organic carbon by continental erosion. Global Biogeochemical Cycles, 10 (1), 23-41. doi:10.1029/95GB02925, http://dx.doi.org/10.1029/95GB02925

Luo, X. J., Chen, S. J., \& Mai, B. X. (2005). Distribution and sources of polycyclic aromatic hydrocarbons in sediments from rivers of Pearl River delta and sea. Environmental Science, 25, 129-134.

Ma, Mei., \& Tong Zhonghua. (1997). Toxicity Estimation of Organism of Changlejiang Water and Sediment Samples. Environmental Chemistry, 16 (2), 167-171.

Mcnally, D. L., Mihelcic, J. R., \& Lueking, D. R. (1999). Biodegradation of mixtures of polycyclic aromatic hydrocarbon under aerobic and nitrate-reducing conditions. Chemosphere, 38 (6), 1313-1321. doi:10.1016/S0045-6535(98)00532-3, http://dx.doi.org/10.1016/S0045-6535(98)00532-3

Morris, J. T., Bowden, W. B. \& A, mechanistic. (1986). Numerical model of sedimentation, mineralization and decomposition for marsh sediments. Soil Science Society of America Journal, 50, 96-105. doi:10.2136/sssaj1986.03615995005000010019x, http://dx.doi.org/10.2136/sssaj1986.03615995005000010019x

Niu, Zhenguo. \& Zhang, Zulu. (1997). Discussion of Some Problems of Lake Environment of China .Geogrphy and Country Research, 13(4), 46-50.

Paolo, M., Shigeru, M., \& Kuninao, T. (2002). Semidiurnal dynamics of salinity, nutrients and suspended particulate matter in an estuary in the seto inland sea,Japan, during a spring tide cycle. Journal of oceanography, 58, 389-402. doi:10.1023/A:1015826212267, http://dx.doi.org/10.1023/A:1015826212267

Pierre, S., \& Josette, G. (2006). Organic carbon and bacterial heterotrophic activity in the maximum turbidity zone of the Seine estuary (France). Aquatic Science, 68, 78-85.

Ploug, H. H., Zimmermann, T., \& Schweitzer, B. (2002). Microbial communities and respiration on ates in the Elbe estuary, Germany. Aquatic Microbial Ecol, 27, 241-248. doi:10.3354/ame027241, 
http://dx.doi.org/10.3354/ame027241

Plummer, D. H., Owens, N. J. R., \& Herbert, R. A. (1987). Bacteria particle interactions in turbid estuarine environments. Estuarine Coastal Shelf Seience, 7, 1429-1433.

Poeton, T. S., Stensel, H. D. \& Strand, S. E. (1999). Biodegradation of polyaromatic hydrocarbons by marine bacteria: effect of solid phase on degradation kinetics. Water Research, 33 (3), 868-880. doi:10.1016/S0043-1354(98)00232-2, http://dx.doi.org/10.1016/S0043-1354(98)00232-2

Qiu, Zunan., Zhang, Zhongyan., \& Qi, Deyao. (1998). Pollutant Distribution Features and Their Correlations of Bottom Silt in Suzhou River. Shanghai Environmental Science, 17(2), 10-14.

$\mathrm{Qu}$, Jiuhui.(2000). Complex pollution and Its Control of Chinese Water. Impact of Science on Society.1, 36-40.

Rieley, q., Collier, R. J., \& Jones, D. M. (1991). Sources of sedimentary lipids deduced from stable carbon isotope analyses of individual compounds. Nature, 352, 425-427.

Saliot, A., Mejanelle, L., \& Scribe, P. (2001). Particulate organic carbon, sterols, tatty acids and pigments in the Amazon River system. Biogeochemistry, 53, 79-103. doi:10.1023/A:1010754022594, http://dx.doi.org/10.1023/A:1010754022594

Smith, S C., Ainsworth, C C., \& Traina, S J. (1992). Effect of sorption on the biodegradation of Quinoline.Soil Science Society of America Journal, 56, 737-746. doi:10.2136/sssaj1992.03615995005600030011x, http://dx.doi.org/10.2136/sssaj1992.03615995005600030011x

Vollcman, J. K., Johns, R. B., \& Gillan, F. T. (1980). Microbial lipids of an intertidal sediment. I. Fatty acids and hydrocarbons. Geochimica et Cosmochimica Acta, 44, 113-1143.

Wang, H. J., Yang, Z. S., \& Li, Y. H. (2007). Dispersal pattern of suspended sediment in the shear frontal zone off the Huanghe (Yellow River) mouth. Continental Shelf Research, 27, 854-871. doi:10.1016/j.csr.2006.12.002, http://dx.doi.org/10.1016/j.csr.2006.12.002

Wang, Hongdao. (1990). Primary Analysis of Recent Changes of Chinese Lakes. Chinese Journal of Oceanology and Limnology, 21(6), 522-528.

Wu, Genfu., Wu, Xuelü., \& Jin, Chengtao. (1998). Research of Released Phosphor in Bottom Slit in West Lake of Hangzhou. Chinese Environmental Science, 18(2), 107-110.

Xu, Ying., Wu, Wenzhong., Zhang, Yinhua. \& Zhang, Fuyuan. (1999). Residue Developments and Long-term End-results of Hexachloridecyclohexane in Duck Lake Area. Journal of Hydrobiology, 23(4), 337-345.

Yuan, Xuyin. (2000). Basic Estimation of Polluted Situation of China Lakes. Geology and Mineral of Volcano, 21(2), 128-136.

Yunker, M. B., \& Macdonald, R. W. (1995). Composition and origins of polycyclic aromatic ydrocarbons in the Mackenzie River and on the Beaufort Sea shelf. Arctic, 48, 118-129.

Zhang, Bing., Zheng, Minghui., Liu, Fanyan., Bao, Zhicheng., \& Xu, Xiaobai. (2001). Penta Distribution in Medium in Environment of Tongting Lake. Chinese Environmental Science, 21(2), 165-167.

Zhang, Licheng., Zhang, Shen., Dong, Wenjiang., \& Zhao, Guijiu. (1986). Main Geochemical Factors of Heavy Metal Transformation in Xiangjiang Water. Journal of Environmental Science, 6(4), 395-402.

Zhu, Lizhong., Xu, Xia., \& Hu, Xiong. (2000). Absorption Property and its Mechanism of Silt in West Lake for Aniline and Phenol. Environmental Science, 20(2), 28-31. 